\title{
The Dynamic Programming Models for Inventory Control System with Time-varying Demand
}

\author{
Truong Hong Trinh (Corresponding author) \\ The University of Danang, University of Economics, Vietnam \\ Tel: 84-236-352-5459_E-mail: trinh.th@due.edu.vn
}

Received: February 21, 2017 Accepted: March 16, 2017

doi:10.5296/ber.v7i1.10965

URL: https://doi.org/10.5296/ber.v7i1.10965

\begin{abstract}
The concept of dependent and independent demand is important in inventory planning and replenishment that also requires different inventory control solutions. This paper employs the dynamic programming technique for inventory control system with time-varying demand to propose the replenishment policy in terms of the economic order quantity, number of replenishment, and reorder point where total inventory cost is minimized. The study result indicates that the dynamic programming models outperform the traditional lot sizing models in terms of total inventory cost. Moreover, the paper creates opportunities for extending further researches on dynamic inventory related to capacity constraints and uncertainty conditions of demand, yield, lead time.
\end{abstract}

Keywords: Dynamic inventory, Lot sizing, Order point system, Material requirement planning, Dynamic programming model, Inventory control system

\section{Background}

In business management, inventory consists of a list of goods and materials held available in stock. The key questions of what and how much inventory are related. Planning is undertaken to determine the level of inventory that will be needed for operations, and replenishment is the process of maintaining this level through some combinations of reorder and other techniques. To determine the level of inventory needed for operations, it is useful to identify the source of the demand. The concept of dependent and independent demand is important in inventory planning and replenishment. An item has independent demand when we can not control it or tie it directly to another item's demand. While an item has dependent demand when the demand for an item is controlled directly, or tied to the production of something else. Therefore, inventory systems with independent demand and dependent demand also require very different solutions. 


\section{Al Macrothink}

Business and Economic Research

ISSN 2162-4860

2017, Vol. 7, No. 1

There is an abundant literature on inventory control policies which extend since the 30's. The details on these policies may refer to research of Peterson and Silver (1979), and research of Zipkin (2000). In inventory planning and replenishment, the traditional lot sizing models are mostly used for inventory control systems. Each lot sizing method outperforms under some assumptions and demand conditions in which the demand does not present a monotonous behavior and varies from period to period. There is also some literature that studies dynamic inventory control policies based on the investigations of Karlin (1960) and Scarf (1959). Wagner and Whitin (1958) introduced a dynamic programming model in which demand is a function of time. Silver and Meal (1973) proposed a heuristic method that finds the optimal order quantity, minimizing the storage and delivery costs. These deterministic and stochastic models strongly relied on mathematical background that is not easy to understand and implement the optimal inventory control policies in reality. This paper attempts to develop the dynamic programming models for both independent inventory system and dependent inventory system with time-varying demand. These models are evaluated with traditional lot sizing models such as Lot for Lot (LFL), Economic Order Quantity (EOQ), Period Order Quantity (POQ), and Minimum Cost per Period (MCP). The paper provides a basic framework for extending dynamic inventory researches with capacity constraints and uncertainty conditions of demand, yield, lead time.

\section{Order Point System (OPS)}

Order Point System (OPS) is the inventory control system for the independent demand. The multi-period inventory model with time-varying demand is developed to propose the replenishment policy in terms of order quantity, number of replenishment, and reorder point. Figure 1 illustrates the typical independent inventory system that has several end-items with independent demand.

A multi-period inventory model with time-varying demand for outsourcing materials is modified on the basis of Wagner's model (Wagner, 1969) under the following assumptions.

1. Backorder is not allowed.

2. Lead time is known with certainty, and assumed constant during the planning horizon.

3. All relevant costs are assumed constant at each period during the planning horizon.

4. No safety stock is assumed.

5. Ordering and holding costs per period are known.

6. Purchase cost is negligible since prices are assumed constant at each period during the planning horizon.

7. Inventory level at each period is assumed constant in each period.

8. No quantity discount is allowed.

9. Cost of capital is not considered. 


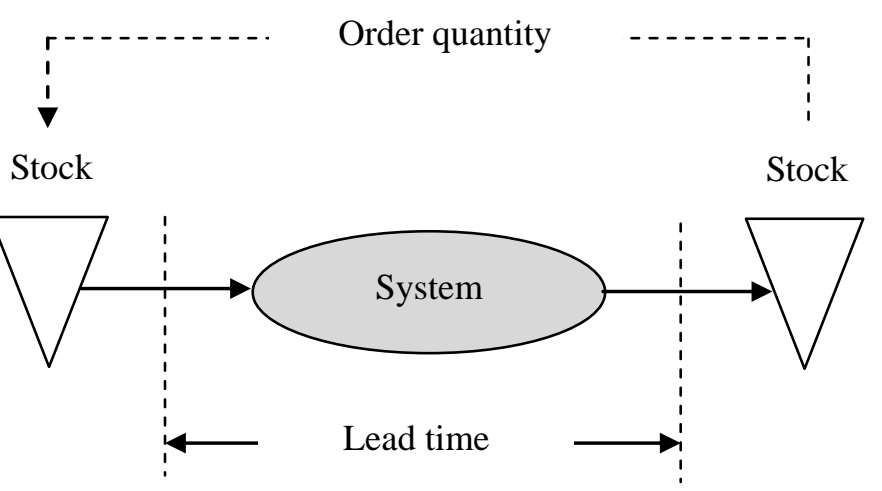

Figure 1 . The independent inventory system

The dynamic programming model for the independent inventory system (OPS) can be expressed as follows.

Minimize:

$$
\sum_{i=1}^{m} \sum_{t=1}^{T} O_{i} \times N_{i, t}+\sum_{i=1}^{m} \sum_{t=1}^{T} H_{i} \times X_{i, t}
$$

Subject to:

$$
\begin{gathered}
X_{i, t}=X_{i, t-1}-D_{i, t}+Q_{i, t} ; \forall i=1 . . m, \forall t=1 . . T \\
R_{i, t}-Q_{i, t+L T_{i}}=0 \quad ; \forall i=1 . . m, \forall t=1 . . T-L T_{i} \\
Q_{i, t} \geq N_{i, t} \times L S_{i} \quad ; \forall i=1 . . m, \forall t=1 . . T \\
Q_{i, t} \leq N_{i, t} \times M \quad ; \forall i=1 . . m, \forall t=1 . . T \\
X_{i, t} \geq 0, Q_{i, t} \geq 0, \text { and } N_{i, t}=(0,1) \quad ; \forall i=1 . . m, \forall t=1 . . T
\end{gathered}
$$

Where,

$\mathrm{O}_{\mathrm{i}}=$ Ordering cost per replenishment for item $\mathrm{i}$ at period $\mathrm{t}^{\text {th }}$

$\mathrm{H}_{\mathrm{i}}=$ Holding cost per unit for item $\mathrm{i}$ at period $\mathrm{t}^{\text {th }}$

$\mathrm{N}_{\mathrm{i}, \mathrm{t}}=$ Number of orders taking place for item $\mathrm{i}$ at period $\mathrm{t}^{\text {th }}$

$D_{i, t}=$ Demand for item $\mathrm{i}$ at period $\mathrm{t}^{\text {th }}$

$\mathrm{Q}_{\mathrm{i}, \mathrm{t}}=$ Order quantity each time an order takes place for item $\mathrm{i}$ at period $\mathrm{t}^{\text {th }}$

$X_{i, t}=$ Inventory level for item $i$ at the end of period $t^{\text {th }}$

$\mathrm{LT}_{\mathrm{i}}=$ Lead time for each replenishment for item $\mathrm{i}$ at period $\mathrm{t}^{\text {th }}$ 
$\mathrm{R}_{\mathrm{i}, \mathrm{t}}=$ Reorder point for item $\mathrm{i}$ at period $\mathrm{t}^{\mathrm{th}}$

$\mathrm{t}=$ Period of time during the planning horizon

$\mathrm{m}=$ Total number of items

$\mathrm{T}=$ Total number of period of time during the planning horizon

The multi-period inventory system under study has three products (end-items) with independent demand. These items have lumpy demand due to seasonality, trend, and economic conditions. Information about demand and properties of the system are given as inputs of the inventory control models. Table 1 gives the demand of three end-items in next eight periods.

Table 1. The demand of items in the planning horizon

\begin{tabular}{|l|l|l|l|l|l|l|l|l|}
\hline Item & 1 & 2 & 3 & 4 & 5 & 6 & 7 & 8 \\
\hline A & 200 & 200 & 300 & 300 & 350 & 350 & 400 & 400 \\
\hline B & 300 & 300 & 300 & 300 & 300 & 300 & 300 & 300 \\
\hline C & 200 & 250 & 300 & 350 & 350 & 300 & 250 & 200 \\
\hline
\end{tabular}

The properties of the inventory system provide information related to inventory costs, initial inventory, lead time and lot size. This information is given in Table 2.

Table 2. The properties of the independent inventory system

\begin{tabular}{|c|c|c|c|c|c|}
\hline Item (i) & $\begin{array}{c}\text { Ordering cost } \\
\left(\mathrm{O}_{\mathrm{i}}\right)\end{array}$ & $\begin{array}{c}\text { Holding cost } \\
\left(\mathrm{H}_{\mathrm{i}}\right)\end{array}$ & $\begin{array}{c}\text { Initial Inventory } \\
\left(\mathrm{X} \mathrm{O}_{\mathrm{i}}\right)\end{array}$ & $\begin{array}{c}\text { Lead time } \\
\left(\mathrm{LT}_{\mathrm{i}}\right)\end{array}$ & $\begin{array}{c}\text { Lot size } \\
\left(\mathrm{LS}_{\mathrm{i}}\right)\end{array}$ \\
\hline $\mathrm{A}$ & 1000 & 2 & 200 & 1 & 100 \\
\hline $\mathrm{B}$ & 1500 & 3 & 600 & 2 & 100 \\
\hline $\mathrm{C}$ & 2000 & 5 & 400 & 1 & 100 \\
\hline
\end{tabular}

There are many different methods for determining replenishment policy such as Lot for Lot (LFL), Economic Order Quantity (EOQ), Period Order Quantity (POQ), and Minimum Cost per Period (MCP). These lot sizing methods are used to compare with the dynamic programming model that is called the OPS model. Table 3 shows the total cost of models under the study. The result indicates that the OPS model is better than other lot sizing models in terms of total inventory cost.

Table 3. Total inventory cost of the models under the study

\begin{tabular}{|c|c|c|c|c|c|}
\hline Method & LFL & EOQ & POQ & MCP & OPS \\
\hline Item A & 7000 & 9580 & 6100 & 6100 & 6100 \\
\hline Item B & 9900 & 12660 & 8100 & 8100 & 8100 \\
\hline Item C & 15000 & 16800 & 17500 & 13500 & 13000 \\
\hline Total cost & 31900 & 39040 & 31700 & 27700 & 27200 \\
\hline
\end{tabular}

\section{Material Requirement Planning (MRP)}

Material Requirement Planning (MRP) is used for the dependent inventory system. The MRP 


\section{Macrothink}

Business and Economic Research

ISSN 2162-4860

2017, Vol. 7, No. 1

model uses a lot of data about items and components. The term of "item" is used to refer to final product, components and components of components. For each item, it needs to know:

- The lead time, the time leg between the release of an order to the shop floor or to a supplier and the receipt of the items.

- The lot size, a minimum production quantity (referred to as a minimum lot size for items that are manufactured in-house) or a minimum order quantity for purchased items.

- The inventory status (stock on hand that calculates based on initial inventory, scheduled receipt and demand requirement in each period).

- Components needed, which is often referred to as a bill of materials (BOM).

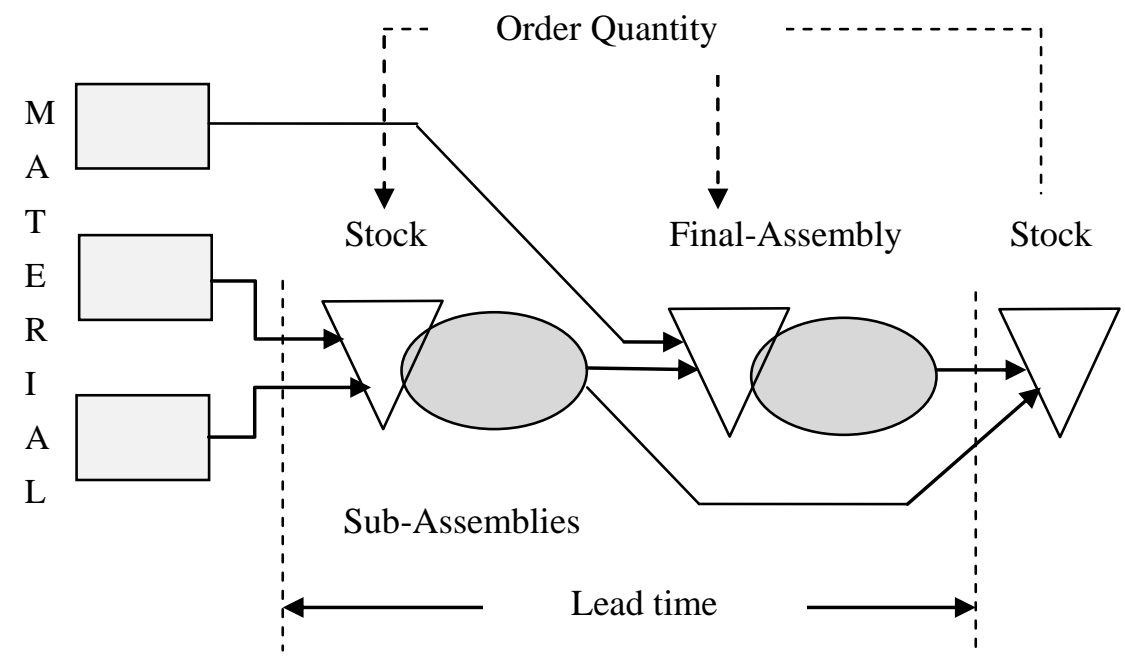

Figure 2. The dependent inventory system

An optimization inventory model is not needed to use MRP calculation, the purpose of the study is to create an optimization problem that matches MRP not for its own sake but to get started with models that match classic planning systems. Using this model as a starting point, it is easy to go on to more sophisticated models (Voß and Woodruff, 2006).

The dynamic programming model for the dependent inventory system (MRP) can be expressed as follows.

Minimize:

$$
\sum_{i=1}^{m} \sum_{t=1}^{T} O_{i} \times N_{i, t}+\sum_{i=1}^{m} \sum_{t=1}^{T} H_{i} \times X_{i, t}
$$

Subject to:

$$
X_{i, t}=X_{i, t-1}-\left(D_{i, t}+\sum_{j=1}^{m} P_{i, j} \times R_{j, t}\right)+Q_{i, t} \quad ; \forall i=1 . . m, \forall t=1 . . T
$$




$$
\begin{gathered}
R_{i, t}-Q_{i, t+L T_{i}}=0 \quad ; \forall i=1 . . m, \forall t=1 . . T-L T_{i} \\
Q_{i, t} \geq N_{i, t} \times L S_{i} \\
Q_{i, t} \leq N_{i, t} \times M \quad ; \forall i=1 . . m, \forall t=1 . . T \\
X_{i, t} \geq 0, Q_{i, t} \geq 0, \text { and } \forall N_{i, t}=(0,1) ; \forall i=1 . . m, \forall t=1 . . T
\end{gathered}
$$

Where,

$\mathrm{O}_{\mathrm{i}}=$ Ordering cost per replenishment for item $\mathrm{i}$ at period $\mathrm{t}^{\text {th }}$

$\mathrm{H}_{\mathrm{i}}=$ Holding cost per unit for item $\mathrm{i}$ at period $\mathrm{t}^{\text {th }}$

$\mathrm{N}_{\mathrm{i}, \mathrm{t}}=$ Number of orders taking place for item $\mathrm{i}$ at period $\mathrm{t}^{\text {th }}$

$Q_{i, t}=$ Order quantity each time an order takes place for item $i$ at period $t^{\text {th }}$

$\mathrm{X}_{\mathrm{i}, \mathrm{t}}=$ Inventory level for item $\mathrm{i}$ at the end of period $\mathrm{t}^{\text {th }}$

$D_{i, t}=$ External demand for item $i$ at period $t^{\text {th }}$

$P_{i, j}=$ Number of item $i$ need to make one $j$

$\mathrm{R}_{\mathrm{i}, \mathrm{t}}=$ Reorder point for item $\mathrm{i}$ at period $\mathrm{t}^{\text {th }}$

$\mathrm{LT}_{\mathrm{i}}=$ Lead time for each replenishment for item $\mathrm{i}$

$\mathrm{LS}_{\mathrm{i}}=$ Minimum lot size for item $\mathrm{i}$

$\mathrm{M}=\mathrm{A}$ large number

$\mathrm{t}=$ Period of time during the planning horizon

$\mathrm{m}=$ Total number of items

$\mathrm{T}=$ Total number of period of time during the planning horizon

The multi-stage inventory system is considered to illustrate the inventory control policy with time-varying demand. Suppose that there is a single end-item A that has a bill of materials as shown in Figure 3. 


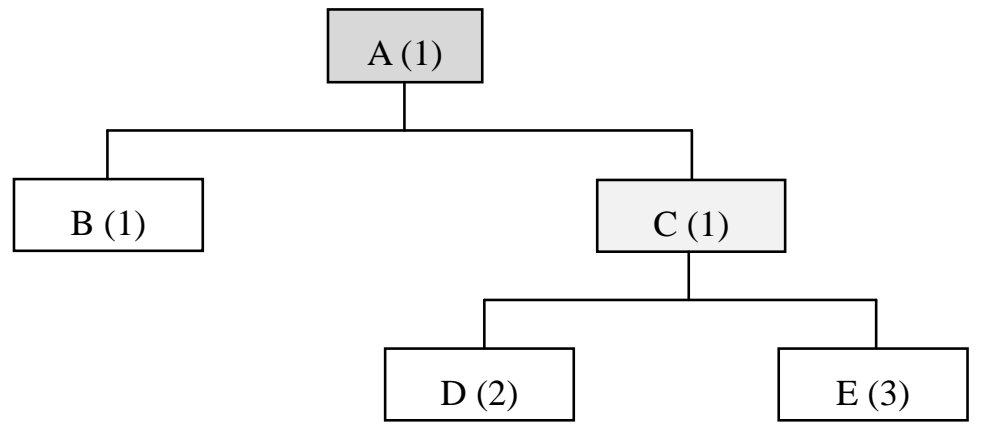

Figure 3. BOM structure for the system

In this system, there are two items with independent demand, A and B. Item B is also a component to make end-item A, so item $\mathrm{B}$ has both dependent and independent demand. The assembly of $A$ requires 1 item $B$ and 1 item $C$. In order to assembly 1 item $C$, it requires 2 items $\mathrm{D}$ and 3 items $\mathrm{E}$. Items $\mathrm{B}, \mathrm{D}, \mathrm{E}$ are raw materials that are ordered from outside suppliers. Table 4 describes the properties of the inventory system.

Table 4. The properties of the dependent inventory system

\begin{tabular}{|c|c|c|c|c|c|}
\hline Item (i) & $\begin{array}{c}\text { Ordering cost } \\
\left(\mathrm{O}_{\mathrm{i}}\right)\end{array}$ & $\begin{array}{c}\text { Holding cost } \\
\left(\mathrm{H}_{\mathrm{i}}\right)\end{array}$ & $\begin{array}{c}\text { Initial Inventory } \\
\left(\mathrm{XO}_{\mathrm{i}}\right)\end{array}$ & $\begin{array}{c}\text { Lead time } \\
\left(\mathrm{LT}_{\mathrm{i}}\right)\end{array}$ & $\begin{array}{c}\text { Lot size } \\
\left(\mathrm{LS}_{\mathrm{i}}\right)\end{array}$ \\
\hline $\mathrm{A}$ & 1000 & 8 & 300 & 1 & 100 \\
\hline $\mathrm{B}$ & 1500 & 6 & 600 & 2 & 100 \\
\hline $\mathrm{C}$ & 1800 & 5 & 400 & 1 & 100 \\
\hline $\mathrm{D}$ & 1300 & 4 & 500 & 1 & 100 \\
\hline $\mathrm{E}$ & 2000 & 7 & 600 & 2 & 100 \\
\hline
\end{tabular}

The demand for item A and item B in the next eight periods is given in Table 5.

Table 5. The demand for item A and item B in the planning horizon

\begin{tabular}{|c|c|c|c|c|c|c|c|c|}
\hline Item & 1 & 2 & 3 & 4 & 5 & 6 & 7 & 8 \\
\hline A & 200 & 0 & 300 & 300 & 350 & 350 & 0 & 400 \\
\hline B & 0 & 300 & 0 & 300 & 300 & 0 & 300 & 0 \\
\hline
\end{tabular}

Based on information about bill of materials (BOM) and data from Table 4 and Table 5, the MRP model provides optimal solution for scheduled receipts, stock on hand and planned order release in each period. The optimal inventory model is developed for such system based on previous dynamic programming model. The objective of the model is to match demand requirements and minimize total inventory cost.

The effectiveness of MRP model is depended on lot sizing methods. Some traditional lot sizing methods are used to compare lot sizing generating in the MRP model under total inventory cost. Lot sizing methods are employed in the study including Lot for Lot (LFL), Period Order Quantity (POQ), and Minimum Cost per Period (MCP). Table 6 shows total inventory cost of the models under the study. 
Table 6. Total inventory cost of the models under the study

\begin{tabular}{|c|c|c|c|c|c|}
\hline Method & LFL & EOQ & POQ & MCP & MRP \\
\hline Item A & 6600 & 6952 & 6600 & 6600 & 9800 \\
\hline Item B & 10200 & 11244 & 10200 & 10200 & 7800 \\
\hline Item C & 10200 & 19622 & 12350 & 10150 & 9650 \\
\hline Item D & 7100 & 6624 & 4600 & 5900 & 3400 \\
\hline Item E & 12300 & 10200 & 8200 & 10200 & 4000 \\
\hline Total cost & 46400 & 54642 & 41950 & 43050 & 34650 \\
\hline
\end{tabular}

The above result indicates that the MRP model has the least total inventory cost. It reveals that the MRP model is better than other models with proposed lot sizing methods in terms of total inventory cost. Moreover, it is interested in extending the MRP model to more sophisticated models with capacity constraints.

\section{Conclusions}

The paper has developed the dynamic programming models for both the independent and independent inventory systems. These dynamic programming models are very basic for extending to sophisticated inventory control models. Some findings are summarized as follows.

For the independent demand, the dynamic programming model for the independent inventory system (OPS) is developed for the multi-period inventory model with time-varying demand. The result indicates that the OPS model provides the optimal inventory solution in terms of total inventory cost. Moreover, the model may extend to inventory control policy with uncertainties in demand, yield and lead time. (Babai and Dallery, 2006). According to the assumptions of the model, its application is limited to some cases in practice, especially the accuracy of the forecasted demand in each period. However, it is found that the model can provide an alternative replenishment policy with significant saving to the decision maker in managing their system efficiently.

For the dependent demand, there is no perfect model for Material Requirement Planning. In fact, the MRP model has a number of well-known and very severe problems. Perhaps the two most serious problems are that lot sizing can cause nervousness and there are no capacity constraints. Even having serious problems, optimal MRP model can still be very useful for solving the lot sizing problems. For one thing, it is usually much better than non-planning model at all. This is particularly true in industries with changing demand patterns where standard orders cannot be used. The MRP model provides a good starting point for planning and for the ordering of raw materials. The study result indicates that the MRP model is better than other traditional lot sizing models as a whole. In addition, using this model as a starting point, it is easy to go on to more sophisticated models, especially capacity constraints.

\section{References}

Babai, M. Z., \& Dallery, Y. (2006). A dynamic inventory control policy under demand, yield and lead time uncertainties. In Service Systems and Service Management, 2006 International 


\section{Macrothink}

Business and Economic Research

ISSN 2162-4860

2017, Vol. 7, No. 1

Conference on (Vol. 2, pp. 1026-1031). IEEE. https://doi.org/10.1109/icsssm.2006.320649

Karlin, S. (1960). Dynamic inventory policy with varying stochastic demands. Management Science, 6(3), 231-258. https://doi.org/10.1287/mnsc.6.3.231

Peterson, R., \& Silver, E. A. (1979). Decision systems for inventory management and production planning. New York: Wiley.

Scarf, H. (1959). The optimality of (S, s) policies in the Dynamic Inventory Problem. Mathematical Methods in the Social Sciences, Stanford University Press, Stanford, California.

Silver, E. A., \& Meal, H. C. (1973). A heuristic for selecting lot size quantities for the case of a deterministic time-varying demand rate and discrete opportunities for replenishment. Production and Inventory Management, 14(2), 64-74.

Voß, S., \& Woodruff, D. L. (2006). Introduction to computational optimization models for production planning in a supply chain (Vol. 240). Springer Science \& Business Media.

Wagner, H. M. (1969). Principles of operations research: with applications to managerial decisions. In Principles of operations research: with applications to managerial decisions. Prentice-Hall.

Wagner, H. M., \& Whitin, T. M. (1958). Dynamic version of the economic lot size model. Management science, 5(1), 89-96. https://doi.org/10.1287/mnsc.5.1.89

Zipkin, P. H. (2000). Foundations of inventory management (Vol. 2). New York: McGraw-Hill.

\section{Appendix}

Appendix 1. The OPS Model in Lingo

MODEL:

! The dynamic programming model of independent inventory system;

! Keywords: Order Point System (OPS);

SETS:

! Index of items;

ITEM/1..3/:O,H,X0,LT,LS;

! The planning horizon;

TIME/1..8/;

! Set of item \& time, input \& output;

LINK(ITEM,TIME):D,N,Q,R,X;

ENDSETS

DATA:

! The properties of the system;

$\mathrm{O}, \mathrm{H}, \mathrm{X} 0, \mathrm{LT}, \mathrm{LS}=$

$10002 \quad 200 \quad 1 \quad 100$

$15003 \quad 6002 \quad 100$ 


\section{MIMacrothink}

$200054001 \quad 100$;

! The demand requirements;

$\mathrm{D}=$

$\begin{array}{llllllll}200 & 200 & 300 & 300 & 350 & 350 & 400 & 400\end{array}$

300300300300300300300300

$200 \quad 250 \quad 300 \quad 350350300 \quad 250 \quad 200$;

ENDDATA

! A large number;

$\mathrm{M}=10000$;

! The objective function;

$\mathrm{MIN}=@ \operatorname{SUM}(\operatorname{LINK}(\mathrm{I}, \mathrm{T}): \mathrm{O}(\mathrm{I}) * \mathrm{~N}(\mathrm{I}, \mathrm{T}))+@ \operatorname{SUM}(\mathrm{LINK}(\mathrm{I}, \mathrm{T}): \mathrm{H}(\mathrm{I}) * \mathrm{X}(\mathrm{I}, \mathrm{T}))$;

! The constraints for inventory status;

$@$ FOR(ITEM(I):X(I,1)=X0(I)-D(I,1)+Q(I,1));

@FOR(LINK(I,T)|T \#LT\# @SIZE(TIME):X(I,T+1)=X(I,T)-D(I,T+1)+Q(I,T+1));

! The constraints for planned order release;

@FOR(ITEM(I):R(I,1)=@SUM(TIME(T)|T \#LE\# LT(I)+1:Q(I,T)));

@FOR(LINK(I,T)|T \#GT\# LT(I)+1:R(I,T-LT(I))=Q(I,T));

! The constraints for scheduled receipts;

@ FOR $(\operatorname{LINK}(\mathrm{I}, \mathrm{T}): \mathrm{Q}(\mathrm{I}, \mathrm{T})>=\mathrm{N}(\mathrm{I}, \mathrm{T}) * \mathrm{LS}(\mathrm{I}) ; \mathrm{Q}(\mathrm{I}, \mathrm{T})<=\mathrm{N}(\mathrm{I}, \mathrm{T}) * \mathrm{M})$;

! The decision variables;

@FOR(LINK(I,T):@GIN(X);@GIN(Q));

@FOR(LINK(I,T):@BIN(N));

END

Source: Author's work

Appendix 2. The MRP Model in Lingo

MODEL:

! The dynamic programming model of dependent inventory system

! Keywords: Material Requirement Planning (MRP);

SETS:

! Index of items;

ITEM/1..5/:O,H,X0,LT,LS;

! The planning horizon;

TIME/1..8/;

! Set of item \& time, input \& output;

LINK(ITEM,TIME):D,N,Q,R,X;

! Bill of material structure;

PART(ITEM,ITEM):P;

ENDSETS

DATA:

! The properties of the system;

$\mathrm{O}, \mathrm{H}, \mathrm{X} 0, \mathrm{LT}, \mathrm{LS}=$

$10008 \quad 300 \quad 1 \quad 100$ 
$15006 \quad 600 \quad 2 \quad 100$

$\begin{array}{llll}18005 & 400 & 1 & 100\end{array}$

$13004 \quad 500 \quad 1 \quad 100$

200076002 100;

! The demand requirements;

$\mathrm{D}=$

$\begin{array}{llllllll}200 & 0 & 300 & 300 & 350 & 350 & 0 & 400\end{array}$

$\begin{array}{llllllll}0 & 300 & 0 & 300 & 300 & 0 & 300 & 0\end{array}$

$\begin{array}{llllllll}0 & 0 & 0 & 0 & 0 & 0 & 0 & 0\end{array}$

$\begin{array}{llllllll}0 & 0 & 0 & 0 & 0 & 0 & 0 & 0\end{array}$

$\begin{array}{llllllll}0 & 0 & 0 & 0 & 0 & 0 & 0 & 0 ;\end{array}$

! Bill of material structure;

$\mathrm{P}=$

$\begin{array}{lllll}0 & 0 & 0 & 0 & 0\end{array}$

$\begin{array}{lllll}1 & 0 & 0 & 0 & 0\end{array}$

$\begin{array}{lllll}1 & 0 & 0 & 0 & 0\end{array}$

$\begin{array}{lllll}0 & 0 & 2 & 0 & 0\end{array}$

$\begin{array}{lllll}0 & 0 & 3 & 0 & 0\end{array}$

ENDDATA

! A large number;

$\mathrm{M}=10000$;

! The objective function;

$\mathrm{MIN}=@ \operatorname{SUM}(\operatorname{LINK}(\mathrm{I}, \mathrm{T}): \mathrm{O}(\mathrm{I}) * \mathrm{~N}(\mathrm{I}, \mathrm{T}))+@ \operatorname{SUM}(\mathrm{LINK}(\mathrm{I}, \mathrm{T}): \mathrm{H}(\mathrm{I}) * \mathrm{X}(\mathrm{I}, \mathrm{T}))$;

! The constraints for inventory status;

@FOR(ITEM(I):X(I,1)=X0(I)-D(I,1)-@SUM(ITEM(J):P(I,J)*R(J,1))+ Q(I,1));

@ FOR(LINK(I,T)|T \#GT\# 1:X(I,T)=X(I,T-1)-D(I,T)-

$@ \operatorname{SUM}(\operatorname{ITEM}(\mathrm{J}): \mathrm{P}(\mathrm{I}, \mathrm{J}) * \mathrm{R}(\mathrm{J}, \mathrm{T}))+\mathrm{Q}(\mathrm{I}, \mathrm{T}))$;

! The constraints for planned order release;

@FOR(ITEM(I):R(I,1)=@SUM(TIME(T)|T \#LE\# LT(I)+1:Q(I,T)));

@FOR(LINK(I,T)|T \#GT\# LT(I)+1:R(I,T-LT(I))=Q(I,T));

! The constraints for scheduled receipts;

@ FOR(LINK(I,T):Q(I,T)>=N(I,T)*LS(I);Q(I,T)<=N(I,T)*M);

! The decision variables;

@FOR(LINK(I,T):@GIN(X); @GIN(Q));

@FOR(LINK(I,T): @BIN(N));

END

Source: Author's work

\section{Copyright Disclaimer}

Copyright for this article is retained by the author(s), with first publication rights granted to the journal.

This is an open-access article distributed under the terms and conditions of the Creative Commons Attribution license (http://creativecommons.org/licenses/by/3.0/). 